\title{
A Holistic Approach to Polymeric Material Selection for Laser Beam Machining using Methods of DEA and TOPSIS
}

\author{
Manish Kumar Roy ${ }^{1}$, Ishwer Shivakoti ${ }^{1}$, Ruben Phipon ${ }^{1}$, Ashis Sharma ${ }^{1}$
}

\begin{abstract}
Laser Beam machining (LBM) nowadays finds a wide acceptance for cutting various materials and cutting of polymer sheets is no exception. Greater reliability of process coupled with superior quality of finished product makes LBM widely used for cutting polymeric materials. Earlier researchers investigated the carbon dioxide laser cutting to a few thermoplastic polymers in thickness varying from $2 \mathrm{~mm}$ to $10 \mathrm{~mm}$. Here, an approach is being made for grading the suitability of polymeric materials and to answer the problem of selection for LBM cutting as per their weightages obtained by using multi-decision making (MCDM) approach. An attempt has also been made to validate the result thus obtained with the experimental results obtained by previous researchers. The analysis encompasses the use of non-parametric linear-programming method of data envelopment analysis (DEA) for process efficiency assessment combined with technique for order preference by similarity to an ideal solution (TOPSIS) for selection of polymer sheets, which is based on the closeness values. The results of this uniquely blended analysis reflect that for $3 \mathrm{~mm}$ thick polymer sheet is polypropelene (PP) to be highly preferable over polyethylene (PE) and polycarbonate (PC). While it turns out to be that polycarbonate (PC) to be highly preferable to other two polymers for $5 \mathrm{~mm}$ thick polymer sheets. Hence the present research analysis fits very good for the polymer sheets of $3 \mathrm{~mm}$ thickness while it deviates a little bit for the $5 \mathrm{~mm}$ sheets.
\end{abstract}

Keywords: Laser Beam Machining. Polymers, DEA, AHP, TOPSIS, MCDM.

\section{Introduction}

Laser Beam Machining is a widely used un-conventional machining process with exceptional qualities of surface finish. The efficiency of cutting process using LBM depends not only on the melting rate but also on debris removal rate from the machining zone i.e. cut kerf. In present days LBM shows an important application area of laser in materials processing with respect to its market share. Some of the production and manufacturing needs in the car and ship manufacturing calls for cutting metals viz. low alloy steel, stainless steel, aluminium and various alloys. Laser cutting is proving to be very valuable among extensive variety of businesses and plastic industries are no exception. Laser beam machining turns out to be very beneficial for plastic industries for the fabrication of product having not only

${ }^{1}$ Department of Mechanical Engineering, Sikkim Manipal Institute of Technology, Sikkim Manipal University, East Sikkim, India 
superior quality but also reliable process [13]. To estimate the workability using laser for few polymeric materials, an exhaustive experimental investigation on three materials viz. polypropelene (PP), polyethylene (PE) and polycarbonate (PC) was carried out. In their experimentations, the author used $\mathrm{CO}_{2}$ laser beam on various polymeric materials with varying thickness ranging from $2 \mathrm{~mm}$ to $10 \mathrm{~mm}$ and concluded that the workability of PC is highest, PP is medium-high and PE the least workable [5].

Grey Relational Analysis was applied for optimization of $\mathrm{CO}_{2}$ laser cutting of $6 \mathrm{~mm}$ thick polymethyl methacrylate (PMMA) for performances characteristics viz. surface roughness and optical transmittance ratio. The research concluded on the rate of flow of assisted gas with focussed beam depth have a bearing on the surface quality for the direct laser cutting process [11]. It was suggested that $\mathrm{CO}_{2}$ lasers having low intensity can be simply utilized for non-metal cutting where plastic board is no exception [40]. In general, it seems that cutting of all polymers can be done by combining vaporization, fusion, and chemical degradation $[1,28]$. Few researchers [15] explored the quality of cut for PMMA using $\mathrm{CO}_{2}$ laser and presented the surface quality features of cutting with laser in both linear and two-dimensional aspect. The cutting speed and the laser power should be properly optimized if one wants to achieve dimensional accuracy with an enhancement in surface quality and roughness values [23]. Few researchers [12] conducted experiments on acrylonitrile butadiene styrene (ABS) and sheets of PMMA by selecting assist gas pressure, laser power, stand-off distance and cutting speed as process variable and studied their effect on taper and hole circularity. In this research investigation optimum combination of process variables which produced lower taper was also reported, the larger hole circularity was determined at entrance than at exit in case of ABS and vice-versa in PMMA. Cutting of fiber strengthened plastics by laser was studied and by a unique technique of digital image process technique for assessment of quality of cut [19].

There are many situations in the real scenario when there are several alternatives to select from under conflicting criteria and in such situations the decision maker often gets tangled to zero into a particular solution. Under such situations a branch of operations research called MCDM is useful enough for the decision maker to decide the best solution. Analytical Hierarchy Process (AHP) coupled with Technique for order performance by similarity to ideal solution (TOPSIS) was applied for estimation of an assembly line balancing methods [33]. Analysis of significant strategies for technology push in context to Indian manufacturing for sustainable development was performed using TOPSIS and VIKOR techniques [35]. Few researchers [29] applied fuzzy AHP coupled with Quality Function Deployment (QFD) for NTM process selection. Various Multi Criteria Decision Making (MCDM) methods viz. AHP, AHP Entropy, VIKOR, Entropy VIKOR and TOPSIS have been used for comparison and evaluation of environmental impacts on a pilot organization [20]. For finding the requirement of customer and its ratings few companies used various techniques and Conjoint analysis [10]. An incorporated approach of QFD and analytic network process (ANP) has been used to interpret customer needs and the technical requirements [36]. An integrated methodology using the efficacy of the fuzzy integral method and the distance approach method for decision making and has been compared with TOPSIS and Grey Relational Analysis (GRA) [24]. By applying the integrated method of fuzzy AHP and QFD earlier researchers [30] performed non-traditional machining process selection from customer's viewpoint. The ease with which any material can be machined if known prior hand, then it becomes a cakewalk for the production manager to take decision on time while selecting a particular machining method for a particular material. Otherwise, an 
arduous task of experimenting coupled with even wastages cannot be avoided. The machinability of any material over any machining method also plays a predominant role in deciding its suitability to be recommended as an alternative. At times when a material has been recognized to be machinable enough on a particular type of machine then the quality of machined item depends a lot on the physical configurations, for instance thickness of the material being machined. Keeping in view the problem of ranking the machinability of materials, which are PE, PP and PC in the current scenario of laser machining necessity is felt for application of MCDM methods. Thus, the present paper approaches to solve the problem of selecting the materials and putting them PE, PP and PC in order as per machinability, as has been experimented by [5] by utilizing the methods of data envelopment analysis (DEA) combined with technique for order performance by similarity to ideal solution (TOPSIS). Here in this article plastic sheets of thickness $3 \mathrm{~mm}$ and $5 \mathrm{~mm}$ have been taken separately for the analysis. A hybrid model has been proposed which uses Data Envelopment Analysis (DEA), Analytic Hierarchy Process (AHP) and Technique for order preference by similarity to an ideal solution (TOPSIS). By the application DEA the efficiency values had been estimated wherein melted area and melted volume have been considered as output while the laser power and cutting speed has been considered as input. The efficiency scores thus calculated has been utilized to prepare the weighted decision matrix of TOPSIS which has been used in AHP. The use of AHP enables determination of weights of the various power levels. TOPSIS has been used such that the power required for machining is a nonbeneficial criterion, so for finding the positive ideal solution and negative ideal solution the opposing values are considered. As such, a hybridization of the three methods had been done such that best ordering of machining sheets on LBM can be estimated based on thickness and the material type.

\section{Data Envelopment Analysis}

Data Envelopment Analysis (DEA) is a very popular management tool of operation research which uses linear programming model and is commonly applied to calculate the efficiency of decision-making units (DMU) or producers. Its application varies from evaluation of performances to benchmarking, however with passage of time it has evolved as a tool for production efficiency measurement. Efficiency measurement has been a subject of great interest since time immemorial as it affects the productivity of organizations. There are certain advantages of using DEA which encompasses no information regarding involved cost and is essential as well as the output and inputs can be simultaneously analysed. Also, the efficiency can be relatively defined and is comparable to best observation made. The basic approaches in DEA can be viewed in two aspects of modelling where one is oriented for input minimization for obtaining a satisfactory level of output, while the other aspect is oriented for output maximization without an increase in the inputs [25]. A substantial amount of work has been carried out in the field of DEA as it utilizes an alternate multi criteria decision making for gaining insight [14]. Conventional MCDM methods have been found to be in good comparison with DEA as well as a very little amount of information is required in case of DEA [32]. DEA has a unique edge over various other approaches that involve parameters and aids in optimizing the observations individually, as it doesn't require an individual function that fits in all observations in best manner [8]. 
An activity-based analysis approach majorly confined the solutions and discussions to only a single output situation [16]. However, few researchers [9] worked on the multiple-input and multiple-output and introduced a powerful methodology that was called data envelopment analysis (DEA). Since Data Envelopment analysis is helpful enough for the measurement of relative efficiencies in a group of similar decision-making units so the efficiency score in case of several inputs and outputs is defined as:

$$
\text { Efficiency }=\frac{\text { Weighted total }(\text { Outputs })}{\text { Weighted total }(\text { Inputs })}
$$

Having a premise initially that let there exists ' $m$ ' decision making units (DMU), which respectively have ' $p$ ' input and ' $t$ ' output, then the comparative efficiency score of a test DMU ' $q$ ' can be evaluated by resolving the subsequent model as under [9].

$$
\begin{aligned}
& \max \frac{\sum_{k=1}^{t} b_{k} y_{k q}}{\sum_{j=1}^{p} a_{j} x_{j q}} \quad \text { subject to } \quad \frac{\sum_{k=1}^{t} b_{k} y_{k i}}{\sum_{j=1}^{p} a_{j} x_{j i}} \leq 1 \forall i \\
& b_{k}, a_{j} \geq 0 \quad \forall k, j
\end{aligned}
$$

Where,

$k=1$ to $\underline{t}, j=1$ to $p$ and $i=1$ to $m$

$y_{k i}=$ quantity of output $k$ created by DMU $i$,

$x_{j i}=$ quantity of input $j$ used by DMU $i$,

$b_{k}=$ weight specified to output $k$,

$a_{j}=$ weight specified to input $j$.

Each DMU is allowed to decide the highest promising weights of its own, and by doing this it gets bound to expose its strength and weakness of its area where it wants to stress or destress for the maximization of its efficiency.

This small program given in equation (2) can be transformed to direct form as:

$$
\begin{gathered}
\max \sum_{k=1}^{t} b_{k} y_{k q} \quad \text { subjected to } \sum_{j=1}^{p} a_{j} x_{j q}=1 \\
\sum_{k=1}^{t} b_{k} y_{k i}-\sum_{j=1}^{p} a_{j} x_{j i} \leq 0 \quad \forall i \\
b_{k}, a_{j} \geq 0 \quad \forall k, j
\end{gathered}
$$


Here the condition sets in an upper limit for the relative efficiency score. The program mentioned above is re-iterated for ' $m$ ' number of times for estimating the relative efficiency values of all the DMUs. Input and output weights may be given to each one of DMU in order to maximize its efficiency. An efficiency score of 1 is a competent DMU and if it is less than 1 then it implies the DMU is incompetent.

\section{Analytic Hierarchy Process (AHP)}

The Analytic Hierarchy Process (AHP) uses a very basic approach of decision making which helps a decision maker to set his priorities. It is one of the most popular analytical technique for intricate, multi-criteria and messy problems of decision making. Here, a decision maker can capture both the subjective and objective priorities for coming to a solution [31]. The key steps that forms the basics of AHP but are fundamental enough and includes: (i) Analyse and breakdown an intricate problem of decision making in a stepwise manner called hierarchy, which has goals, the means of achieving it and the criteria. (ii) Performing pairwise comparisons keeping priorities in view, between available alternatives for the determination of preference on relative basis. (iii) Integration of preferences for the development of a comprehensive assessment of decision alternatives. This above described stepwise method is highly applicable for analysis of intricate multi-attribute alternatives that may involve the criteria which are subjective in nature. This method emphasizes on the determination of priorities called weightages of different prompting attributes. The power and the flexibility of AHP exists wherein the weightages and the final ranking are derived because of pairwise relative comparisons among the various criteria and options as provided by a user. For assigning preference values to each power level for the various sheet thickness alternatives and in order to generate the decision making matrix to aid for performing pairwise comparisons, use of terms like 'much more important' are adopted to draw out the decisionmakers inclinations. An effective AHP framework for Non -Traditional Machining (NTM) selection confined to material and machining constraints and accompanied with expert system development has been studied [6]. The use of AHP also gave a well-balanced selection method on various criteria and sub-criteria, a methodology that aids designers in deciding the best material alternatives for the body in white panels of automobiles [27]. For an appropriate selection of robots, an aggregate method incorporating AHP and QFD has been employed for a specific job which endeavoured to ascertain whether or not industrial robot deployment proved helpful for increasing performance from the perspective of specific requirement [4]. An amalgamated method of AHP and TOPSIS has been proposed for a particular blend of work material and shape feature concerning NTM process selection taking into consideration the various attributes essential for it [7]. In general, the AHP models use the following steps:

Step-1: Construct a matrix by comparing the relative significance keeping in view the scale of preference. Taking say ' $n$ ' conditions, the paired assessment of condition $i$ with condition $j$ gives a matrix $A I$ which is square and here, $d_{i j}$ represents relative preference of condition $i$ in reference to condition $j$. Here in this matrix $d_{i j}=1$, when $i=j$ and $d_{j i}=1 / d_{i j}$. 


$$
A I=\left[\begin{array}{cccc}
d_{11} & d_{12} & \ldots \ldots \ldots . & d_{1 n} \\
d_{21} & d_{22} & \ldots \ldots \ldots \ldots & d_{2 n} \\
\ldots \ldots \ldots \ldots \ldots \ldots \ldots & \ldots \ldots \ldots \ldots \ldots \ldots & \ldots \ldots \ldots \ldots & d_{n n}
\end{array}\right]
$$

Step-2: By using a normalization method, a relative normalized matrix is then created by dividing the elements of a column of the pair wise assessment matrix by the sum of elements of column.

Step-3: Determination of priority vector (PV), which is an average of individual row elements comprising the normalized matrix. The row averages thus obtained are the PV of alternative preferences with regard to a specific criterion. The sum of all PVs is always 1.

Step-4: For every row in the paired preference matrix, a weighted sum is evaluated by adding up the products of the elements with PV to its respective alternative column element.

Step-5: For each row, the weighted sum as obtained in previous step is divided by its PV of corresponding (row) alternative.

Step-6: The result of previous step is then averaged to find $\lambda_{\max }$.

Step-7: The consistency index (C.I.) is then computed for $\mathrm{n}$ alternatives by

$$
C . I .=\frac{\left(\lambda_{\max }-n\right)}{(n-1)}
$$

Step-8: The reliability is then determined by a ratio which shows the consistency (C.R.) is then evaluated by $C . R .=\frac{\text { C.I. }}{\text { R.I. }}$ Where, random index $(R . I$.$) depends on number of alternatives$ as given below.

Random index (R.I.) for number of alternatives $(n)$

$\begin{array}{ccccccc}\mathrm{N} & 3 & 4 & 5 & 6 & 7 & 8 \\ \text { R.I. } & 0.58 & 0.90 & 1.12 & 1.24 & 1.32 & 1.41\end{array}$

\section{Technique for order preference by similarity to an ideal solution (TOPSIS)}

TOPSIS being a powerful technique for solving multi-attribute or multi-criteria decision making (MADM/MCDM) problems of today's world [18]. It provides aid to the decision 
maker(s) to systematize the problem to be explained, analyze it, and compare the positioning of the alternatives so that, the best possible alternative may be selected [34]. The real logic of TOPSIS is awe simple. This approach makes it possible to determine the best option by finding the nearest one to most optimistic solution and the least preferred one uses to be one which is farthest away to negative ideal solution [3]. The idea originated with perception that the displaced ideal point from where the compromise solution has the smallest distance [2, 39]. Further it was proposed that the alternative which is closest to the positive ideal solution but farthest from the negative ideal solution could be preferred in this method [18]. Positive ideal solution is a set of best value of criteria while negative ideal solution is a set of poorest values obtained of criteria [17].Earlier researchers have used fuzzy TOPSIS for ranking of suppliers of hip prosthesis, and software supportive model was proposed to support the developed model [38]. MCDM problems, like assortment of third-party logistics have been carried out using a hybrid model of fuzzy analytic hierarchy process (FAHP) and TOPSIS. Here, use of triangular fuzzy numbers has been done [21]. To estimate ranking of the service quality of various travel website a relative investigation of TOPSIS as well as fuzzy TOPSIS has been carried with the help of an example [22]. An approach based on fuzzy TOPSIS has been proposed for ranking and sequencing of the processes followed at service centres of End-Of-Life vehicles, as it has bearing on the efficiency of the whole system [37]. Any multi criteria decision making problem which has $m$ alternates as possible options ( $O_{1}, O_{2}, O_{3}$, $\left.O_{m}\right)$ but they all need to be verified on $n$ number of conditions $\left(P_{1}, P_{2}, P_{3}, \ldots \ldots, P_{n}\right)$ then such situation can be rather considered to be matrix structure of $m$ options across $n$ conditions. Wherein, any particular element of the matrix $a_{i j}$ states the measure of accomplishment of $i^{\text {th }}$ alternate, $A_{i}$, with reference to the $j^{\text {th }}$ condition, $P_{j}$ as has been illustrated below.

$$
\begin{aligned}
& \begin{array}{lllllll}
P_{1} & P_{2} & P_{3} & \text {. } & \text {. } & P_{n}
\end{array} \\
& D=\begin{array}{c}
O_{1} \\
O_{2} \\
O_{3} \\
\cdot \\
\cdot \\
\cdot \\
O_{m}
\end{array}\left[\begin{array}{ccccccc}
a_{11} & a_{12} & a_{13} & \cdot & \cdot & \cdot & a_{1 n} \\
a_{21} & a_{22} & a_{23} & \cdot & \cdot & \cdot & a_{2 n} \\
a_{31} & a_{32} & a_{33} & \cdot & \cdot & \cdot & a_{3 n} \\
\cdot & \cdot & \cdot & \cdot & \cdot & \cdot & \cdot \\
\cdot & \cdot & \cdot & \cdot & \cdot & \cdot & \cdot \\
\cdot & \cdot & \cdot & \cdot & \cdot & \cdot & \cdot \\
a_{m 1} & a_{m 2} & a_{m 3} & \cdot & \cdot & \cdot & a_{m n}
\end{array}\right]
\end{aligned}
$$

Here, it is worth mentioning that any of the alternates $O_{1}$ through $O_{m}$ are in spirit do not at all depend on each other and their application is mutually exclusive. Whereas the conditions $P_{1}$ through $P_{n}$ signifies the various conditions over which a particular alternate can be judged upon. Following are the steps involved for solving a problem by TOPSIS in reference with the point discussed above:

Step 1. Identify and obtain the performance data of all alternatives on various involving criteria or conditions for formulation of a decision matrix.

Step 2. Construct the normalized decision matrix using any of normalization methods or vector normalization method as it isolates the conditions to normal i.e. 


$$
r_{i j}=\frac{x_{i j}}{\sqrt{\sum_{i=1}^{m} x_{i j}^{2}}}, \quad i=1, \ldots ., m ; j=1, \ldots ., n
$$

On doing this the various dimensional entities of the various conditions are brought down to non-dimensional platform which allows a better comparison.

Step 3. A set of weighted normalized decision matrix is then constructed with either already provided criteria weight $w_{j}$ or calculated by some means say through AHP.

Step 4. Establish the positive ideal solution $B_{J}^{+}$and negative ideal solution $B_{J}^{-}$.

$$
\begin{gathered}
B_{J}^{+}=\left\{b_{1}^{+}, \ldots \ldots, b_{n}^{+}\right\}=\left\{\max \left(b_{i j}\right) \text { if } j \in J ; \min \left(b_{i j}\right) \text { if } j \in J^{\prime}\right. \\
B_{J}^{-}=\left\{b_{1}^{-}, \ldots \ldots, b_{n}^{-}\right\}=\left\{\min \left(b_{i j}\right) \text { if } j \in J ; \max \left(b_{i j}\right) \text { if } j \in J^{\prime}\right.
\end{gathered}
$$

where $J$ is linked with the beneficial criteria which is higher-the-better and $J$ 'is linked with the cost criteria and is non-beneficial in aspect and it is expected to be lower-the-better; $i=1, \ldots, m$ and $j=1, \ldots, n$.

Step 5. Compute the separation measure for the positive ideal solution and negative ideal solution

$$
S_{i}^{+}=\sqrt{\sum_{j=1}^{n}\left(b_{i j}-b_{j}^{+}\right)^{2}} \text { and } S_{i}^{-}=\sqrt{\sum_{j=1}^{n}\left(b_{i j}-b_{j}^{-}\right)^{2}}
$$

Step 6. Compute the relative closeness coefficient $C_{i}{ }^{*}$ to the ideal solution and rank the alternatives in downward order. Relative closeness can be calculated by:

$$
C_{i}^{*}=\frac{S_{i}^{-}}{S_{i}^{+}+S_{i}^{-}} \text {for } i=1, \ldots, m
$$

\section{Methodology}

The methods discussed above have been integrated and are applied in sequential manner. As a first step the efficiency score of PP, PE and PC have calculated using the DEA. For the analysis, and as application example, of above-mentioned MCDM like DEA and TOPSIS methods, the data for laser cutting of the polymeric materials have been utilized from an earlier research [5]. Sheets of thickness $3 \mathrm{~mm}$ and $5 \mathrm{~mm}$ have been taken separately for the analysis. The efficiency values have been calculated using DEA where melted area and melted volume have been taken as output while laser power and cutting speed has been considered as input. The experimental data for PP, PE and PC has been taken from table 2, 3 $\& 4$ of the above-mentioned article. DEA being a multi-factor productivity analysis model which can be used as a measure for estimating relative efficiencies in case of a consistent set of decision-making units (DMUs). For estimating the efficiency score following steps have been adopted: 


\section{Polypropylene}

For a $3 \mathrm{~mm}$ sheet of polypropylene the set of input and output values are Input:

The input values considered here are the first set of input values.

Power $=200 \mathrm{~W} ;$ Speed $=2.3 \mathrm{~m} / \mathrm{min}=33.38 \mathrm{~mm} / \mathrm{sec}$

Output:

Melted area $=0.904 \mathrm{~mm}^{2} ;$ Melted volume $=35 \mathrm{~mm}^{3}$

$$
\text { Efficiency, } \in=\frac{0.904 v_{1}+35 v_{2}}{200 u_{1}+33.38 u_{2}} \leq 1
$$

Maximize $\left(0.904 v_{1}+35 v_{2}\right)$ subjected to $0.904 v_{1}+35 v_{2}-\left(200 u_{1}+33.38 u_{2}\right) \leq 0$

Since the output obtained is always less than or equal to $100 \%$ of the input values.

So, $200 u_{1}+33.38 u_{2}=1$

Also, $0.904 v_{1}+35 v_{2}-1 \leq 0$

Where, $v_{1}, v_{2}, u_{1}, u_{2} \geq 0$

Solving the above in-equations three optimum points out of which we get maximum at $(0,0.02857)=0.99995$

And hence, $\in=\frac{0.99995}{1}=0.99995$

\section{Polyethylene}

For a $3 \mathrm{~mm}$ sheet of polyethylene the set of input and output values are Input:

The input values considered here are the first set of input values.

Power $=200 \mathrm{~W} ;$ Speed $=1.03 \mathrm{~m} / \mathrm{min}=17.166 \mathrm{~mm} / \mathrm{sec}$

Output:

Melted area $=1.306 \mathrm{~mm}^{2} ;$ Melted volume $=28 \mathrm{~mm}^{3}$

$$
\text { Efficiency, } \in=\frac{1.306 v_{1}+28 v_{2}}{200 u_{1}+17.66 u_{2}} \leq 1
$$

Maximize $\left(1.306 v_{1}+28 v_{2}\right)$ subjected to; $1.306 v_{1}+28 v_{2}-\left(200 u_{1}+17.66 u_{2}\right) \leq 0$

So, $200 u_{1}+17.66 u_{2}=1$

Also, $1.306 v_{1}+28 v_{2} \leq 1$

Where, $v_{1}, v_{2}, u_{1}, u_{2} \geq 0$

Solving the above cases three optimum points are obtained, of which maximum is at $(0,0.03571)$ and is 1.0000042 .

And hence, $\in=\frac{1.0000042}{1}=1.0000042$ 


\section{Polycarbonate}

For a $3 \mathrm{~mm}$ sheet of polycarbonate the set of input and output values are Input:

The input values considered here are the first set of input values.

Power $=200 \mathrm{~W} ;$ Speed $=3.4 \mathrm{~m} / \mathrm{min}=56.666 \mathrm{~mm} / \mathrm{sec}$

Output:

Melted area $=0.712 \mathrm{~mm}^{2} ;$ Melted volume $=40 \mathrm{~mm}^{3}$

$$
\text { Efficiency, } \in=\frac{0.712 v_{1}+40 v_{2}}{200 u_{1}+56.666 u_{2}} \leq 1
$$

Maximize $\left(0.712 v_{1}+40 v_{2}\right)$ subjected to; $0.712 v_{1}+40 v_{2}-\left(200 u_{1}+56.66 u_{2}\right) \leq 0$

So, $200 u_{1}+56.666 u_{2}=1$

Also, $0.712 v_{1}+40 v_{2} \leq 1$

Where, $v_{1}, v_{2}, u_{1}, u_{2} \geq 0$

Solving the above cases three optimum points are obtained, of which maximum is at $(0,0.25)$ and is 1 .

And hence, $\in=\frac{1}{1}=1$

In the same manner the efficiency values at various power levels are evaluated in case of PP, $\mathrm{PE}$ and PC materials for $3 \mathrm{~mm}$ sheets and are reproduced in Table 1 while that for $5 \mathrm{~mm}$ sheet are in Table 2.

Table 1. Efficiency values for PP, PE and PC sheets of thickness $3 \mathrm{~mm}$

\begin{tabular}{|c|c|c|c|c|c|}
\hline Material & $\begin{array}{l}\text { Power } \\
\text { (W) }\end{array}$ & Efficiency & Material & Power (W) & Efficiency \\
\hline $\mathrm{PP}$ & \multirow{3}{*}{200} & 0.99999576 & $\mathrm{PP}$ & \multirow{3}{*}{500} & 1.00016 \\
\hline $\mathrm{PE}$ & & 1.0000042 & $\mathrm{PE}$ & & 1.0002 \\
\hline $\mathrm{PC}$ & & 1 & $\mathrm{PC}$ & & 0.999999 \\
\hline $\mathrm{PP}$ & \multirow{3}{*}{300} & 1.0002 & PP & \multirow{3}{*}{600} & 0.999999 \\
\hline $\mathrm{PE}$ & & 1.00006 & $\mathrm{PE}$ & & 0.99999915 \\
\hline $\mathrm{PC}$ & & 0.9999978 & $\mathrm{PC}$ & & 0.99999768 \\
\hline $\mathrm{PP}$ & \multirow{3}{*}{400} & 1.00035 & & & \\
\hline $\mathrm{PE}$ & & 1.00032 & & & \\
\hline $\mathrm{PC}$ & & 1.00023 & & & \\
\hline
\end{tabular}

After calculating the efficiency values, the concept of TOPSIS method is separately applied for $3 \mathrm{~mm}$ and $5 \mathrm{~mm}$ sheet, respectively. Table 3 enlists the decision matrix for $3 \mathrm{~mm}$ thick sheet. 
As a next step the columns of each power level corresponding to $3 \mathrm{~mm}$ sheet is then normalized by using $r_{i j}=\frac{x_{i j}}{\sqrt{m}}, i=1, \ldots ., m ; j=1, \ldots ., n$.

$$
\sqrt{\sum_{i=1}^{m} x_{i j}^{2}}
$$

Hence, for 200W power level the denominator for normalization becomes $\sqrt{(0.99999576)^{2}+(1.0000042)^{2}+1^{2}}=1.732$ and the corresponding normalized values of the column one comes out to be $0.577347829,0.577352702$, and 0.577350277 . On similar lines all the elements of the matrix corresponding to the same sheet thickness is normalized.

As a next step the columns of each power level corresponding to $3 \mathrm{~mm}$ sheet is then normalized by using $r_{i j}=\frac{x_{i j}}{\sqrt{m}}, i=1, \ldots ., m ; j=1, \ldots ., n$.

$$
\sqrt{\sum_{i=1}^{m} x_{i j}^{2}}
$$

\begin{tabular}{|c|c|c|c|c|c|}
\hline Material & $\begin{array}{l}\text { Power } \\
\text { (W) }\end{array}$ & Efficiency & Material & $\begin{array}{l}\text { Power } \\
\text { (W) }\end{array}$ & Efficiency \\
\hline $\mathrm{PP}$ & \multirow{3}{*}{200} & 0.99999435 & $\mathrm{PP}$ & \multirow{3}{*}{800} & 0.9999978 \\
\hline $\mathrm{PE}$ & & 1.00008 & $\mathrm{PE}$ & & 1.00001673 \\
\hline $\mathrm{PC}$ & & 1.00018 & $\mathrm{PC}$ & & 0.99999252 \\
\hline $\mathrm{PP}$ & \multirow{3}{*}{300} & 1 & $\mathrm{PP}$ & \multirow{3}{*}{1000} & 1.0000029 \\
\hline $\mathrm{PE}$ & & 1.0000146 & $\mathrm{PE}$ & & 0.99999324 \\
\hline $\mathrm{PC}$ & & 1.00016 & $\mathrm{PC}$ & & 0.99999338 \\
\hline $\mathrm{PP}$ & \multirow{3}{*}{400} & 0.9999913 & $\mathrm{PP}$ & \multirow{3}{*}{1200} & 1.00014 \\
\hline $\mathrm{PE}$ & & 1.0000107 & $\mathrm{PE}$ & & 1.00000544 \\
\hline $\mathrm{PC}$ & & 1.00023 & $\mathrm{PC}$ & & 1.00000656 \\
\hline $\mathrm{PP}$ & \multirow{3}{*}{600} & 1.0000016 & PP & \multirow{3}{*}{1400} & 1.008 \\
\hline $\mathrm{PE}$ & & 1.00035 & $\mathrm{PE}$ & & 0.99998864 \\
\hline $\mathrm{PC}$ & & 1.00013 & $\mathrm{PC}$ & & 1.0000096 \\
\hline
\end{tabular}

Table 2. Efficiency values of PP, PE and PC sheets of thickness 5mm

Table 3. Decision matrix for $3 \mathrm{~mm}$ sheet

\begin{tabular}{|c|l|l|l|l|l|}
\hline \multirow{2}{*}{$\begin{array}{c}\text { Thickness } \\
3 \mathrm{~mm}\end{array}$} & 200 & 300 & 400 & 500 & 600 \\
\cline { 2 - 6 } & \multicolumn{5}{|c|}{ Power (W) } \\
\hline PP & 0.99999576 & 1.0002 & 1.00035 & 1.00016 & 0.999999 \\
\hline PE & 1.0000042 & 1.00006 & 1.00032 & 1.0002 & 0.999999 \\
\hline PC & 1 & 0.999998 & 1.00023 & 0.999999 & 0.999998 \\
\hline
\end{tabular}

Hence, for $200 \mathrm{~W}$ power level the denominator for normalization becomes $\sqrt{(0.99999576)^{2}+(1.0000042)^{2}+1^{2}}=1.732$ and the corresponding normalized 
values of the column one comes out to be $0.577347829,0.577352702$, and 0.577350277 . On similar lines all the elements of the matrix corresponding to the same sheet thickness is normalized.

As a next step the normalized decision matrix in TOPSIS needs to be weighted, so the weights of the various power levels are then evaluated by following the steps of AHP. The decision matrix outlined below is used for estimating the weights of various power levels. Here, it is worth mentioning that a pairwise comparison has been performed to estimate the priorities of various power levels and the significance scores have been awarded as per the Saaty's nine point scale where 1 signifies equal significance, 3 for moderate significance, 5 for strong significance, 7 for very strong significance and 9 extreme significance.

\begin{tabular}{|c|c|c|c|c|}
\hline $3 \mathrm{~mm}$ & 200 & 300 & 400 & 500 \\
\hline 200 & 1 & 3 & 5 & 7 \\
\hline 00 & $1 / 3$ & 1 & 3 & 5 \\
\hline 400 & $1 / 5$ & $1 / 3$ & 1 & \\
\hline 500 & $1 / 7$ & $1 / 5$ & $1 / 3$ & 1 \\
\hline 00 & $1 / 9$ & $1 / 7$ & $1 / 5$ & $1 / 3$ \\
\hline
\end{tabular}

Further, for the use in TOPSIS weights are calculated with AHP and the weights came out to be $0.512813,0.261499,0.128976,0.0633765$ and 0.0333352 for laser power of $200 \mathrm{~W}$, $300 \mathrm{~W}, 400 \mathrm{~W}, 500 \mathrm{~W}$ and $600 \mathrm{~W}$, respectively. Also, the C.I. value was $0.0593688(<0.1)$. After normalization of Table 3 and on multiplying with the corresponding weights the weighted decision matrix is calculated as shown in Table 4.

Table 4. Weighted decision matrix

\begin{tabular}{|c|l|l|l|l|l|}
\hline $3 \mathrm{~mm}$ & 200 & 300 & 400 & 500 & 600 \\
\hline PP & 0.296071472 & 0.150994 & 0.07446805 & 0.036591915 & 0.019246 \\
\hline PE & 0.296073971 & 0.150973 & 0.074465817 & 0.036593378 & 0.019246 \\
\hline PC & 0.296072728 & 0.150963 & 0.074459117 & 0.036586024 & 0.019246 \\
\hline
\end{tabular}

So from table 4 the positive ideal solution $B_{J}^{+} V_{J}^{+}$and the negative ideal solution $B_{J}^{-}$ $V_{J}^{-}$

$$
\begin{gathered}
B_{J}^{+}=(0.296073971,0.150993737,0.07446805,0.036586024,0.019246069) \\
B_{J}^{-}=(0.296071472,0.150963213,0.074459117,0.036593378,0.019246097) \\
V_{J}^{+}=\{0.296073971,0.150993737,0.07446805,0.036586024,0.019246069\} \\
V_{J}^{-}=\{0.296071472,0.150963213,0.074459117,0.036593378,0.019246097\}
\end{gathered}
$$

The separation measure for the positive ideal solution and negative ideal solution is calculated as 


$$
\begin{aligned}
S_{1}^{+} & =\sqrt{\sum_{j=1}^{n}\left(b_{1 j}-b_{j}^{+}\right)} \\
& =\sqrt{\begin{array}{l}
(0.296071472-0.296073971)^{2}+(0.150993737-0.150993737)^{2}+ \\
(0.07446805-0.07446805)^{2}+(0.036591915-0.036586024)^{2}+
\end{array}} \\
& =4.09412 \times 10^{-11} \\
\text { and } & \sqrt{S_{1}^{+}}=\sqrt{\sum_{j=1}^{n}\left(b_{1 j}-b_{j}^{-}\right)} \\
& =\sqrt{\begin{array}{l}
(0.0192460 .019246069)^{2} \\
(0.07446805-0.074459117)^{2}+(0.036591915-0.036593378)^{2}+
\end{array}} \\
& =1.01371 \times 10^{-9}
\end{aligned}
$$

In the same manner the $S_{2,3}^{+}$and $S_{2,3}^{-}$values are calculated and are obtained as follows :

$$
\begin{aligned}
& S_{1,2,3}^{+}=\left[4.09412 \times 10^{-11}, 5.0575 \times 10^{-10}, 1.01311 \times 10^{-9}\right] \\
& S_{1,2,3}^{-}=\left[1.01371 \times 10^{-9}, 1.39302 \times 10^{-10}, 5.5655 \times 10^{-11}\right]
\end{aligned}
$$

The relative closeness coefficient $C_{i}^{*}$ to the ideal solution is then calculated by using

$$
C_{i}^{*}=\frac{S_{i}^{-}}{S_{i}^{+}+S_{i}^{-}} \text {for } i=1, \ldots, m
$$

And the relative closeness values are obtained as shown below and are enlisted in table 5

Table 5. Relative closeness values for $3 \mathrm{~mm}$ thick polymer sheets

\begin{tabular}{|c|c|c|}
\hline Material & Closeness & Rank \\
\hline PP & 0.832662 & 1 \\
\hline PE & 0.344185 & 2 \\
\hline PC & 0.189878 & 3 \\
\hline
\end{tabular}

The same sequence of steps are followed for $5 \mathrm{~mm}$ thickness sheets also the weights calculated by AHP are $0.331325,0.23066,0.157235,0.105903,0.070936,0.047681$, 0.032698 and 0.023563 for laser powers of $200 \mathrm{~W}, 300 \mathrm{~W}, 400 \mathrm{~W}, 600 \mathrm{~W}, 800 \mathrm{~W}, 1000 \mathrm{~W}$, $1200 \mathrm{~W}$ and $1400 \mathrm{~W}$ with C.I. $=0.0411822(<0.1)$. The relative closeness values obtained for $5 \mathrm{~mm}$ sheets are shown in table 6 .

Keeping the above analysis in consideration an alternative analysis was performed to compare the three material sheets (PP, PE, and PC) on the basis of their thickness (T), the power required (P) and the cutting speed (C). Using AHP the weight of the three criterion was calculated. 


$$
\begin{aligned}
& \begin{array}{lll}
T & P
\end{array} \\
& \begin{array}{l}
T \\
P
\end{array}\left[\begin{array}{ccc}
1 & 1 / 3 & 5 \\
3 & 1 & 4 \\
1 / 5 & 1 / 4 & 1
\end{array}\right]
\end{aligned}
$$

The weights obtained for $T, P \& S$ are $0.30848,0.595668, \& 0.0958519$ respectively. For PP the values of $T, P$ and $S$ are enlisted in table 7.

Table 6. Relative closeness values for $5 \mathrm{~mm}$ thick polymer sheets

\begin{tabular}{|c|c|c|}
\hline Material & Closeness & Rank \\
\hline PP & 0.004094 & 3 \\
\hline PE & 0.464891 & 2 \\
\hline PC & 0.782966 & 1 \\
\hline
\end{tabular}

Table 7. Thickness, Power Level and Cutting speed for Poly Propelene sheet

\begin{tabular}{|c|c|c|}
\hline Thickness $(T)$ & Power Level $(P)$ & Cutting Speed $(S)$ \\
\hline 3 & 200 & 2.3 \\
\hline 3 & 300 & 3.3 \\
\hline 3 & 400 & 4.1 \\
\hline 3 & 500 & 5.1 \\
\hline 3 & 600 & 6 \\
\hline 5 & 200 & 1.1 \\
\hline 5 & 300 & 1.6 \\
\hline 5 & 400 & 2 \\
\hline 5 & 600 & 2.9 \\
\hline 5 & 800 & 3.7 \\
\hline 5 & 1000 & 4.5 \\
\hline 5 & 1200 & 5.3 \\
\hline 5 & 1400 & 6.1 \\
\hline
\end{tabular}

The values are then normalized using the regular normalization rule and then normalized values are enlisted in table 8.

$$
r_{i j}=\frac{x_{i j}}{\sqrt{\sum_{i=1}^{m} x_{i j}^{2}}}, \quad i=1, \ldots ., m ; j=1, \ldots . ., n
$$

Following this the weights of $T, P$ and $S$ are considered to find the weighted values of thickness, power required and the cutting speed. Here it is worth mentioning that the power required for machining is a non-beneficial criterion so for finding the positive ideal solution and negative ideal solution the opposing values are considered. 
Table 8. Normalized values of Thickness $(T)$, Power Level $(P)$ and Cutting speed $(S)$ for Poly Propelene sheet

\begin{tabular}{|l|l|l|l|l|l|l|l|l|l|l|l|l|l|}
\hline$T$ & 0.19 & 0.19 & 0.19 & 0.19 & 0.19 & 0.31 & 0.31 & 0.31 & 0.31 & 0.31 & 0.31 & 0.31 & 0.31 \\
\hline$P$ & 0.07 & 0.11 & 0.15 & 0.19 & 0.23 & 0.07 & 0.11 & 0.15 & 0.23 & 0.31 & 0.38 & 0.46 & 0.54 \\
\hline$S$ & 0.15 & 0.22 & 0.28 & 0.35 & 0.41 & 0.07 & 0.11 & 0.13 & 0.19 & 0.25 & 0.31 & 0.36 & 0.42 \\
\hline
\end{tabular}

Hence the positive ideal solution and negative ideal solution as obtained for the PP are enlisted in table 9.

Table 9. Positive ideal solution and negative ideal solution as obtained for PP

\begin{tabular}{|c|c|c|c|}
\hline & Thickness (T) & Power Level (P) & Cutting Speed (S) \\
\hline $\begin{array}{c}\text { Positive Ideal } \\
\left(\mathrm{A}^{+}\right)\end{array}$ & 0.098540321 & 0.046407862 & 0.039537599 \\
\hline $\begin{array}{c}\text { Negative Ideal } \\
\left(\mathrm{A}^{-}\right)\end{array}$ & 0.059124193 & 0.324855032 & 0.007621706 \\
\hline
\end{tabular}

The separation measure for the positive ideal solution and negative ideal solution is calculated as

$$
S_{i}^{+}=\sqrt{\sum_{j=1}^{n}\left(b_{i j}-b_{j}^{+}\right)^{2}} \text { and } S_{i}^{-}=\sqrt{\sum_{j=1}^{n}\left(b_{i j}-b_{j}^{-}\right)^{2}}
$$

and the values thus obtained are as follows:

$$
\begin{aligned}
& S_{i}^{+}=\left[\begin{array}{l}
0.002184126,0.002434372,0.003881973,0.006443096,0.010168826, \\
0.001091577,0.0014226,0.002887666,0.009061869,0.019634706, \\
0.034570812,0.053870185,0.077532827
\end{array}\right] \\
& S_{i}^{-}=\left[\begin{array}{l}
0.077595701,0.065360441,0.054235208,0.044310824,0.035507385, \\
0.079086458,0.066713658,0.055431239,0.036154134,0.021232, \\
0.010673135,0.004477538,0.002645208
\end{array}\right]
\end{aligned}
$$

Following this the relative closeness coefficient $C_{i}^{*}$ to the ideal solution is then calculated by using

$$
C_{i}^{*}=\frac{S_{i}^{-}}{S_{i}^{+}+S_{i}^{-}} \text {for } i=1, \ldots, m
$$

And the relative closeness coefficient values obtained for poly propelene was

$$
C_{i}^{*}=\left[\begin{array}{l}
0.972623077,0.964092058,0.93320438,0.873052251,0.777371501, \\
0.986385583,0.97912125,0.950484905,0.799587135,0.519542733, \\
0.235901945,0.076738859,0.032991684
\end{array}\right]
$$




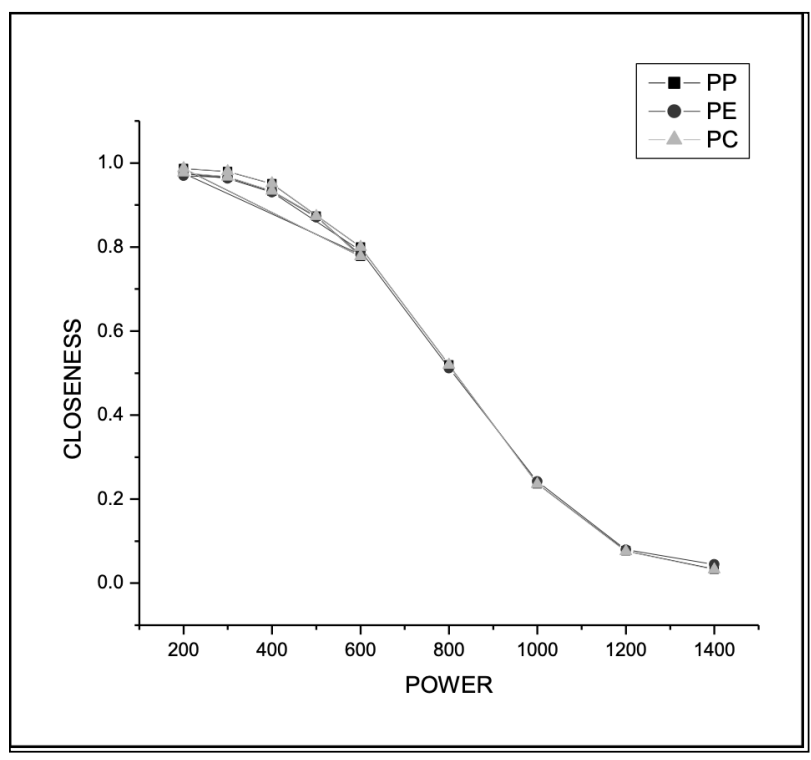

Figure 1 Variation of Closeness coefficient values with respect to power.

Following the same methodology, the closeness coefficient values are determined for rest of the materials also viz. Polyethylene and Poly Carbonate. The values thus obtained are then plotted as shown in figure1.

\section{Conclusion}

Here in the present paper Data Envelopment Analysis has been used as base model for analysis. DEA is a multi-factor analysis model, and it does not need any assumptions which is parametric in nature. However just for the sake of comparison of the proposed integrated model of DEA, AHP and TOPSIS and alternate model comprising only of AHP and TOPSIS has also been proposed. The later model has been found to be in very close agreement with the outcome of the earlier researchers. On comparing the results obtained from table 5 and table 6 with [5] following conclusions may be drawn:

(a). According to [5] depending on surface roughness values, for $3 \mathrm{~mm}$ sheet $\mathrm{PP}>\mathrm{PE}>\mathrm{PC}$ and according to our analysis based on the closeness we are also getting PP $>$ PE $>$ PC.

(b). Also, depending on surface roughness values, for $5 \mathrm{~mm}$ sheet $\mathrm{PE}>\mathrm{PP}>\mathrm{PC}$ and according to our analysis based on the closeness we are getting PC $>$ PE $>$ PP. The efficiency values are extremely affected due to variation in the size of dataset and depends on the type and quantity of input and output factors. However, one of the important deficiencies of DEA lies 
in excessive flexibility that it provides flexibility for selection of weightages for input and output factors [26].

(c). Thus, it can be inferred from the above that the present analysis fits very good for the polymer sheets of $3 \mathrm{~mm}$ thickness while deviation is observed for $5 \mathrm{~mm}$ sheets. However, it can be attributed that with reference to figure 1 the ordering of the materials on the basis of closeness coefficient values still stands out to be $\mathrm{PE}>\mathrm{PP}>\mathrm{PC}$ which is also in close agreement with the results of the earlier researchers.

\section{References}

[1] Atanasov, P. A., \& Baeva, M. G., CW CO2 laser cutting of plastics. In XI International Symposium on Gas Flow and Chemical Lasers and High-Power Laser Conference (Vol. 3092, pp. 772-776). International Society for Optics and Photonics, 1997, April.

[2] Belenson, S. M., \& Kapur, K. C., An algorithm for solving multicriterion linear programming problems with examples. Journal of the Operational Research Society, 24(1), 65-77, 1973.

[3] Benitez, J. M., Martín, J. C., \& Román, C., Using fuzzy number for measuring quality of service in the hotel industry. Tourism management, 28(2), 544-555, 2007.

[4] Bhattacharya, A., Sarkar, B. and Mukherjee, S.K., Integrating AHP with QFD for robot selection under requirement perspective. International journal of production research, 43(17), pp.3671-3685, 2005.

[5] Caiazzo, F., Curcio, F., Daurelio, G., \& Minutolo, F. M. C., Laser cutting of different polymeric plastics (PE, PP and PC) by a CO2 laser beam. Journal of Materials Processing Technology, 159(3), 279-285, 2005.

[6] Chakraborty, S. and Dey, S., Design of an analytic-hierarchy-process-based expert system for non-traditional machining process selection. The International Journal of Advanced Manufacturing Technology, 31(5-6), pp.490-500, 2006.

[7] Chakladar, N. D., \& Chakraborty, S., A combined TOPSIS-AHP-method-based approach for non-traditional machining processes selection. Proceedings of the Institution of Mechanical Engineers, Part B: Journal of Engineering Manufacture, 222(12), 1613-1623, 2008.

[8] Charnes, A., Cooper, W. W., Lewin, A. Y., \& Seiford, L. M. (Eds.)., Data envelopment analysis: Theory, methodology, and applications. Springer Science \& Business Media, 2013.

[9] Charnes, A., Cooper, W. W., \& Rhodes, E., Measuring the efficiency of decision making units. European journal of operational research, 2(6), 429-444, 1978.

[10] Chaudhuri A., \& Bhattacharyya M., A combined QFD and integer programming framework to determine attribute levels for conjoint study, International Journal of Production Research, 47(23), 6633-6649, 2009.

[11] Chen, M. F., Ho, Y. S., Hsiao, W. T., Wu, T. H., Tseng, S. F., \& Huang, K. C., Optimized laser cutting on light guide plates using grey relational analysis. Optics and Lasers in Engineering, 49(2), 222-228, 2011.

[12] Choudhury, I. A., Chong, W. C., \& Vahid, G., Hole qualities in laser trepanning of polymeric materials. Optics and lasers in engineering, 50(9), 1297-1305, 2012. 
[13] Choudhury, I. A., \& Shirley, S., Laser cutting of polymeric materials: an experimental investigation. Optics \& Laser Technology, 42(3), 503-508, 2010.

[14] Cook, W. D., \& Seiford, L. M., Data envelopment analysis (DEA)-Thirty years on. European journal of operational research, 192(1), 1-17, 2009.

[15] Davim, J. P., Oliveira, C., Barricas, N., \& Conceição, M., Evaluation of cutting quality of PMMA using CO2 lasers. The International Journal of Advanced Manufacturing Technology, 35(9-10), 875-879, 2008.

[16] Farrell, M. J., The measurement of productive efficiency. Journal of the Royal Statistical Society: Series A (General), 120(3), 253-281, 1957.

[17] Goh, H. H., Kok, B. C., Yeo, H. T., Lee, S. W., \& Zin, A. M., Combination of TOPSIS and AHP in load shedding scheme for large pulp mill electrical system. International Journal of Electrical Power \& Energy Systems, 47, 198-204, 2013.

[18] Hwang, C. L., \& Yoon, K., Methods for multiple attribute decision making. In Multiple attribute decision making (pp. 58-191). Springer, Berlin, Heidelberg, 1981.

[19] Ilio, A. D., Tagliaferri, V., \& Veniali, F., Machining parameters and cut quality in laser cutting of aramid fibre reinforced plastics. Material and Manufacturing Process, 5(4), 591-608, 1990.

[20] Jovanovic, J., Shah, H., Vujovic, A., \& Krivokapic, Z., Application ofMCDM Methods in Evaluation of Environmental Impacts. International Journal for Quality Research, 8(4), 2014.

[21] Kabir, G., Third Party Logistic Service Provider Selection Using Fuzzy AHP and TOPSIS method. International Journal for Quality Research, 6(1), 2012.

[22] Kabir, G., \& Hasin, M., Comparative Analysis of TOPSIS and Fuzzy TOPSIS for the Evaluation of Travel Website Service Quality. International Journal for Quality Research, 6(3), 2012.

[23] Kurt, M., Kaynak, Y., Bagci, E., Demirer, H., \& Kurt, M., Dimensional analyses and surface quality of the laser cutting process for engineering plastics. The International Journal of Advanced Manufacturing Technology, 41(3-4), 259-267, 2009.

[24] Kumar, M., \& Das, P., Fuzzy-Distance Function Approach for Multiple Criteria Decision Making. International Journal for quality research, 6(2), 2012.

[25] Lee, C., \& Ji, Y. B., Data envelopment analysis in Stata. Stata Conference DC, 2009.

[26] Lim, S., Oh, K. W., \& Zhu, J., Use of DEA cross-efficiency evaluation in portfolio selection: An application to Korean stock market. European Journal of Operational Research, 236(1), 361-368, 2014.

[27] Mayyas, A., Shen, Q., Mayyas, A., Shan, D., Qattawi, A. and Omar, M., Using quality function deployment and analytical hierarchy process for material selection of body-in-white. Materials \& Design, 32(5), pp.2771-2782, 2011.

[28] Powel, S. I., \& Cutting, C. L., LASER 5: Laser Materials Processing for Industry. IITT International Gournay Sur Marne, 54-71, 1989.

[29] Roy, M. K., Ray, A., \& Pradhan, B. B., Non-Traditional Machining Process Selection-An Integrated Approach. International Journal for Quality Research, 11(1), 2017.

[30] Roy, M. K., Ray, A., \& Pradhan, B. B., Non-traditional machining process selection using integrated fuzzy AHP and QFD techniques: a customer perspective. Production \& Manufacturing Research, 2(1), 530-549, 2014. 
[31] Saaty TL, The Analytic Hierarchy Process: Planning, Priority Setting, Resource Allocation, RWS Publication, Pittsburgh, PA, 1988.

[32] Sarkis, J., A comparative analysis of DEA as a discrete alternative multiple criteria decision tool. European journal of operational research, 123(3), 543-557, 2000.

[33] Sharma, P., Thakar, G., \& Gupta, R. C., Evaluation of Assembly Line Balancing Methods Using an Analytical Hierarchy Process (AHP) And Technique For Order Preferences By Similarity To Ideal Solution (TOPSIS) Based Approach. International Journal for Quality Research, 7(4), 2013.

[34] Shih, H. S., Shyur, H. J., \& Lee, E. S., An extension of TOPSIS for group decision making. Mathematical and computer modelling, 45(7-8), 801-813, 2007.

[35] Singla, A., Ahuja, I. S., \& Sethi, A. S., Comparative Analysis of Technology Push Strategies Influencing Sustainable Development in Manufacturing Industries Using TOPSIS and VIKOR Technique. International Journal for Quality Research, 12(1), 2018.

[36] Soota, T., Integrated methodology for product planning using multi criteria analysis. International Journal for Quality Research, 10(3), 547-558, 2016.

[37] Tadić, D., Arsovski, S., Stefanovic, M., \& Aleksic, A., A fuzzy AHP and TOPSIS for ELV dismantling selection. International Journal for quality research, 4(2), 2010.

[38] Zahar Djordjevic, M., Puskaric, H., \& Djordjevic, A., Evaluation and Ranking Of Artificial Hip Prosthesis Suppliers By Using A Fuzzy TOPSIS Methodology. International Journal for Quality Research, 8(2), 2014.

[39] Zelany, M., A concept of compromise solutions and the method of the displaced ideal. Computers \& Operations Research, 1(3-4), 479-496, 1974.

[40] Zhou, B. H., \& Mahdavian, S. M., Experimental and theoretical analyses of cutting nonmetallic materials by low power CO2-laser. Journal of materials processing technology, 146(2), 188-192, 2004.

Received: 24.04.2020, Accepted: 5.10.2020 